\section{Treatment of Noma: medical missions in Ethiopia}

\author{
M. McGurk ${ }^{1}$ and R. Marck ${ }^{2}$
}

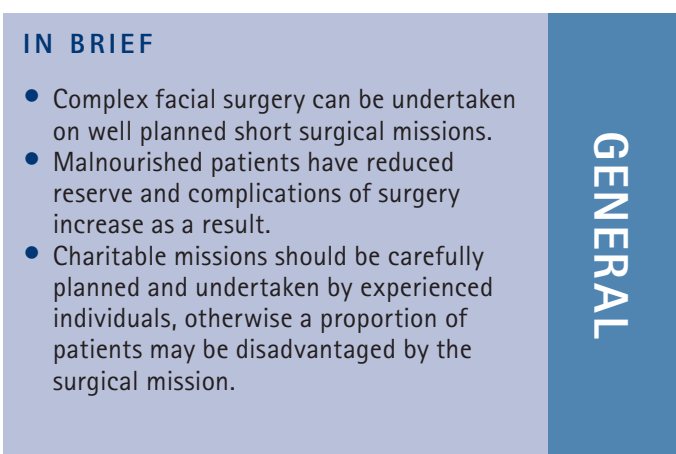

There is a long tradition in medicine and dentistry to support medical missions in developing countries where health care is limited. These journeys facilitate the spread of knowledge and can be voyages of self-discovery. In the past it has been customary to bring patients to developed countries for treatment. This policy has proved expensive as the medical costs incurred to treat a single patient in the UK can match the cost of sending a ten unit surgical team abroad for two weeks. 50 patients may be treated in this period of time so the pattern of practice is now for teams of healthcare workers to move to areas of need rather than the other way round.'

The diseases and deformity conditions commonly treated on such missions are well-circumscribed conditions such as cleft lip and palate, cataracts and fistula surgery. ${ }^{2,3}$ It is unusual to tackle complex medical disorders. This paper describes experience over three years of surgical visits to Ethiopia dealing with complex facial deformity and the problems encountered.

\section{ETHIOPIA}

Ethiopia has a long and dignified biblical history. It covers a land mass of 1.2 million $\mathrm{km}^{2}$ and sits at the commencement of the rift valley of east Africa. Addis Ababa is its capital, residing in the crater of an old volcano. Much of the country lies above 5,000 feet. The land is fertile and supports a population of approximately 85 million people. In contrast wealth is scarce with few cash-crops and mineral reserves. Consequently the gross national product is low and resources to serve the population are limited. Medical facilities are meagre throughout the country. It is suggested

1"Department of Oral \&t Maxillofacial Surgery, King's College London Dental Institute, Tower Wing Floor 23, Guy's Hospital, London, SE1 9RT; ${ }^{2}$ The Surgical Department, St. Lucas Andreas Hospital, Jan Tooropstraat 164, $061 \mathrm{AE}$, Amsterdam

*Correspondence to: Professor Mark McGurk Email: mark.mcgurk@kcl.ac.uk

\section{Refereed Paper}

Accepted 6 January 2010

DOI: $10.1038 /$ sj.bdj.2010.159

${ }^{\circledR}$ British Dental Journal 2010; 208: 179-182 that a body of 127 surgeons serves this whole population. Consequently there is a large contingent of patients with chronic or benign untreated diseases.

The visiting surgical teams work in unison with medical charities and one is Project Harar. It identifies patients in the Harar region of Ethiopia, which has limited resources and a population prone to malnutrition. Those with facial deformity are shunned by their community and are confined to their village or house compounding the patient's plight with a lack of education and access to medical care. The charity targets these individuals who are then brought to Addis Ababa a few weeks before a medical mission is due to arrive.

Medical conditions treated on these missions vary but the principal and most challenging disorder is Noma (Table 1). Noma is a disease that is no longer prevalent in the developed world. ${ }^{4}$ It is an example of unchecked oral infection fuelled by malnutrition and viral infection (measles) which further depresses the patient's immunity. ${ }^{5}$ The initiating factor is thought to be acute

Table 1 Case mix and grading of treatment outcome on three surgical missions to Ethiopia

Case mix:

Noma $=43$

Trauma $=15$

Tumours $=9$

Others (burns, traditional healing,

parasitic infection) $=21$

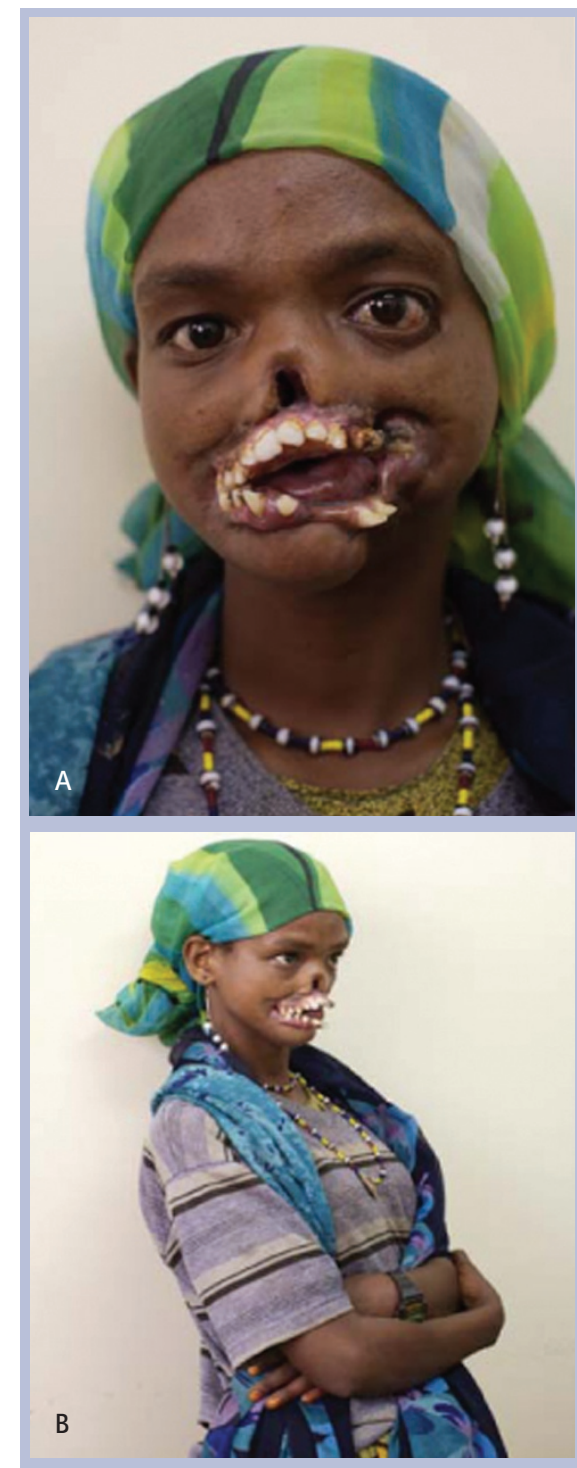

Figs 1a-b In many Noma cases the lips and nose are lost to necrosis 
ulcerative gingivitis. This is unlikely for in many cases the teeth and periodontium are healthy when the lips and nose are lost to necrosis (Fig. 1). The natural history is for an ulcer to develop in the cheek or lip which then spreads rapidly through the soft tissues. The resultant toxins induce local necrosis. It is thought that approximately $90 \%$ of those affected die of disease and the ones that survive suffer dreadful facial deformity. ${ }^{6}$ The large tissue defects that include bone and soft tissue heal by secondary intention (Figs 2a-b). The scar tissue leads to contraction, distorted growth, oro-nasal incompetence and trismus. The trismus is unique in that the ramus of the mandible fuses with the zygoma. The condyle is unaffected (Figs $3 \mathrm{a}-\mathrm{c})$. The condition is quite different to TMJ ankylosis where the mandibular condyle is fused to the glenoid fossa. Other diseases encountered are fibroosseous disorders (Fig. 4) and benign tumours (Fig. 5). There is also a number of children attacked by hyenas resulting in loss of facial tissue. In the rural areas the population is dependent on traditional medicine and in one village a series of patients lost the tips of their noses as a result of the application of battery acid!

\section{PATIENT MANAGEMENT}

Over a period of three years, 95 patients were treated on surgical missions to Addis Ababa. Refinements in management have occurred over this period of time. On the first visit the hospital facilities were impressive but there was a lack of consumables such as antibiotics, antiseptics and material for wound care. On subsequent visits a team of dentists and junior doctors were sent two weeks before the surgical mission to improve nutrition, patient hygiene and to treat the patients for parasitic infections (worms and malaria). Support services were rudimentary and diagnosis depended on clinical examination. There was no access to pathology reports, radiographic images or haemoglobin examination before surgery. The reversion to clinical judgement rather than reliance on sophisticated tests was the first of many useful lessons.

\section{RESULTS}

The results demonstrate that simple operative procedures could be undertaken with relatively low risk of complication.
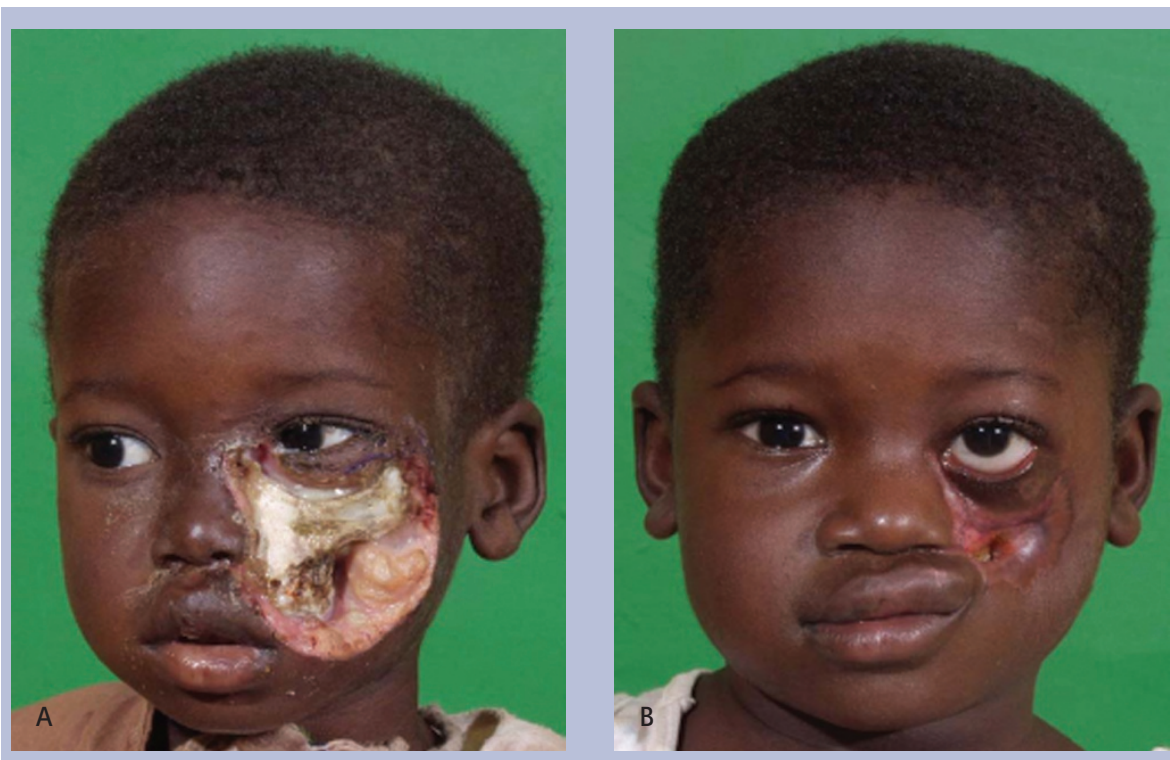

Figs 2a-b Large tissue defects that include bone and soft tissue heal by secondary intention

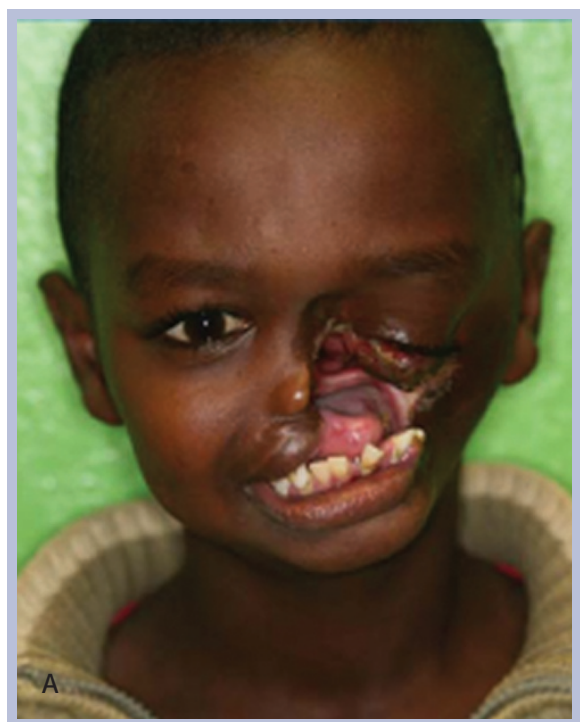

Figs 3a-c The scar tissue leads to contraction, distorted growth, oro-nasal incompetence and trismus. The trismus is unique in that the ramus of the mandible fuses with the zygoma. The condyle is unaffected
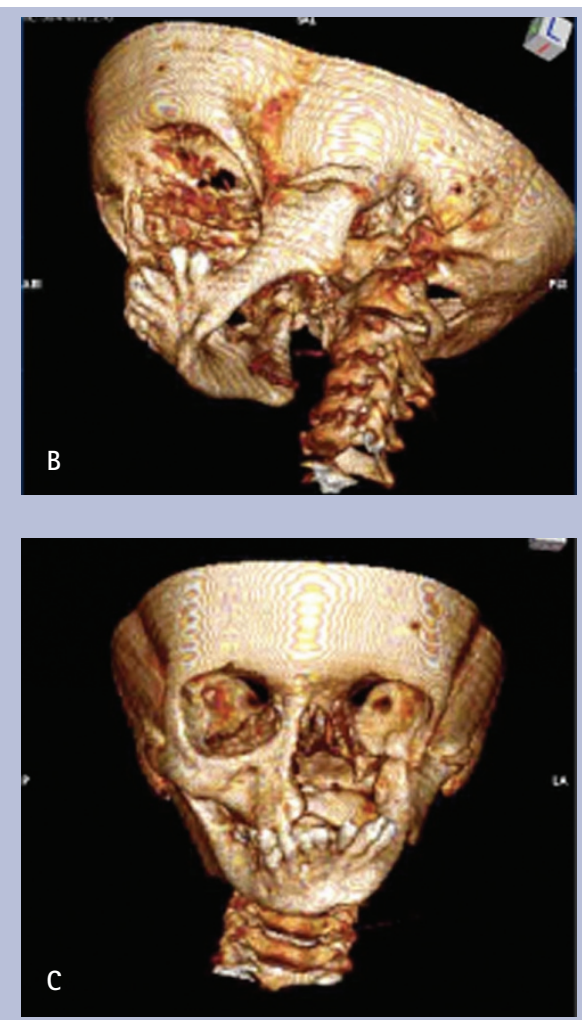

However, complex facial reconstruction for Noma cases was associated with considerable postoperative morbidity. The outcome of treatment was judged on a scale of 1 to 5 (Table 2) based on a photographic record of each patient (before and during surgery, then weekly for a period of 3-5 weeks). Surgical intervention was graded as simple (small local flaps or split skin grafts), or complex (stage reconstruction, the use of distant tissue transfer or rib grafts). Complications were recorded as minor (no extension of hospital stay), intermediate (prolonged hospital stay) and serious (life threatening).

In the period 2007-2009, a total of 35 (37\%) patients had complex and 55 (58\%) simple surgical procedures $(\mathrm{N}=95)$. There were two (2\%) life threatening complications (hyperglycaemic coma, obstructed airway), 36 (38\%) of patients had intermediate grade complications and 19 (20\%) minor events with 32 (34\%) with no recorded complications. All patients with complex surgery had some form of complication whereas 54\% of patients 

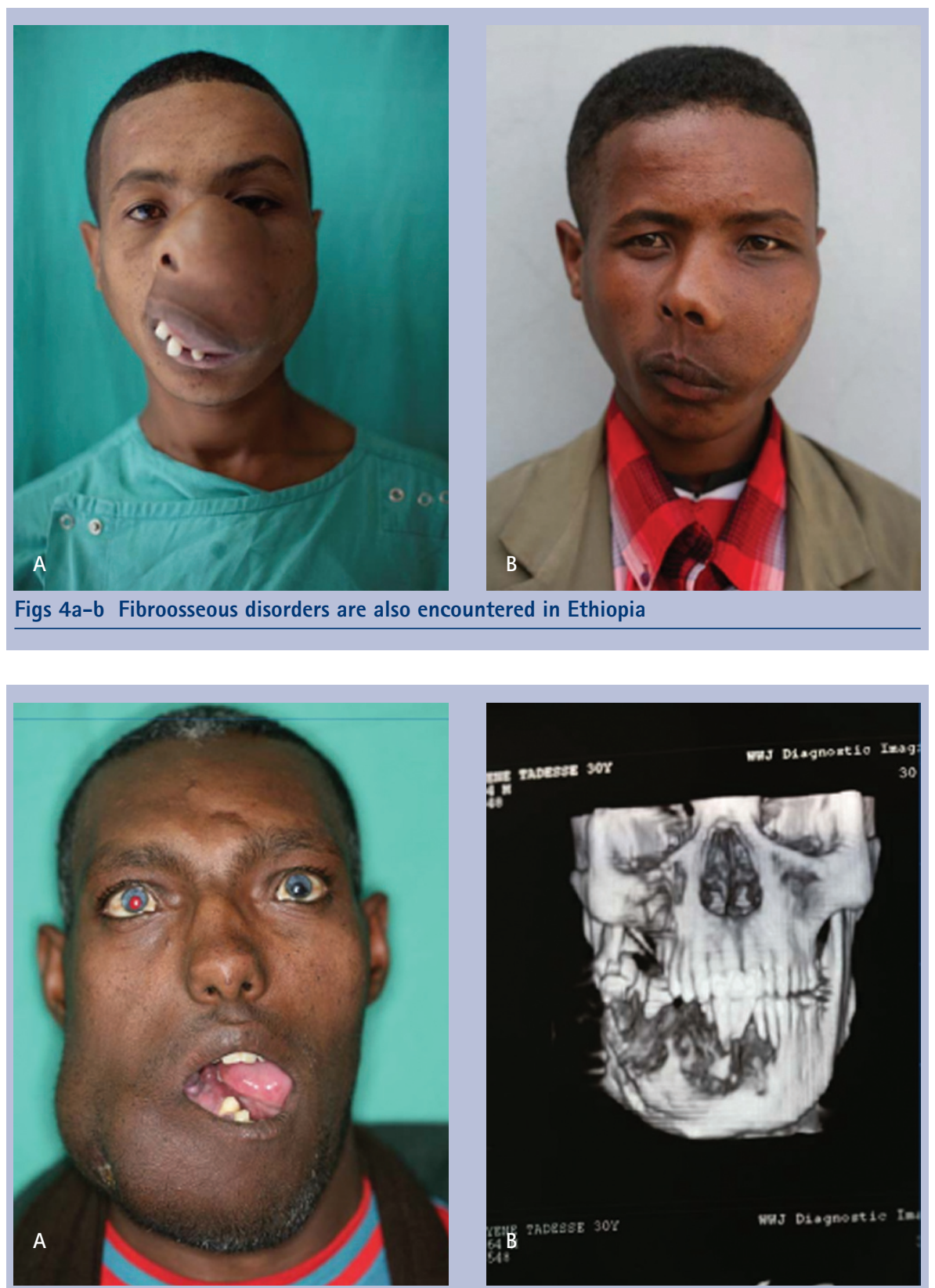

Figs 5a-b An example of a benign tumour encountered in Ethiopia

undergoing simple surgical procedures had no complications.

In terms of outcome, in the simple surgery group 54/60 (90\%) of patients had a good result (grade 1 and grade 2) whereas in the complex surgery group only $14 / 35$ (40\%) had a good outcome. Overall 6/95 (6\%) of patients were judged to have a result similar to their appearance at presentation and a further 6\% a result worse than when they presented to hospital.

\section{DISCUSSION}

The tendency in medical missions is for the team to arrive, work long hours and leave abruptly after two weeks. The immediate positive feedback from the patients and local staff frequently give the members of the team the impression of a high success rate. However, on the missions in question a new policy was adopted which was to leave a junior doctor behind for three weeks following completion of the team visit. ${ }^{7}$ This allowed an evaluation of delayed complications. The results showed that there was a tendency to overvalue the success of a mission. Despite the best of intentions and preparations for surgery, a number of patients treated with complex facial disorders do not achieve an ideal result. Approximately 12\% of patients are left with the same degree of disfigurement or worse after complex surgery. This should be borne in mind when accepting patients that require complex

\section{Table 2 Grading of treatment outcome}

The scale used to judge the outcome

of surgery at 3-5 weeks post-operation:

1) Significantly better than at first presentation. Result is as envisaged

2) Much improved result - minor blemishes

3) Surgical defect remains but improvement over original deformity

4) Deformity remains similar to the time of presentation

5) Condition worse than when patient presented to hospital

facial reconstruction. It is an unfortunate fact of life that as well as doing good a small proportion of patients are adversely affected by surgical missions.

The importance of basic skills in examination was readily apparent in a medical system devoid of modern technology. It was a welcome reminder that basic time tested clinical skills are all important to the practice of medicine and dentistry and reinforce the importance of their place in the teaching curriculum. Paradoxically it is these skills that are being eroded in Western medicine where it is easier to seek a diagnosis by means of an MRI or a cone beam CT scan than carefully examining the patient for signs of disease. To work in Africa is to be resourceful and is a welcome relief from the constraints of inappropriate 'health and safety' dictates. Nasogastric feeding is not dependent on expensive formulated mixtures but can be provided easily by mixtures of liquidised banana, butter and milk providing ample sustenance during the postoperative period.

One of the interesting aspects of these missions is that the gross disease encountered would be similar to that faced by surgeons in the nineteenth century. Many of the wound healing problems encountered are those faced by our medical forbearers. In this context intricate surgical techniques used in developed countries are not as reliable as the more robust pedicle flaps in common use in 1960s and 1990s. Over a period of three surgical visits the delta pectoral flap was replaced by the submental flap which carries less morbidity. ${ }^{8}$ The incidence of complications was reduced as a consequence. The poor nutritional state of most patients means they have limited physical reserve. Consequently long operations are avoided where possible and only one microvascular procedure was undertaken. 
Finally the surgical team had to manage patients that had been shunned by their local communities and in many instances their world had been restricted to their house or village. In this situation the incorporation of young doctors had a remarkable effect. The children were transformed by the attention provided by these young health workers and their disabilities were transiently forgotten. The result of this camaraderie meant that the children appreciated that the surgical intervention was for their benefit and bore the pain and discomfort stoically. In many cases they looked forward to further surgical interventions as a way of escaping the world in which they were otherwise sealed.

\section{SUMMARY}

Teams from Guy's Hospital, Groningen
University, and Leeds participated in three surgical visits to Ethiopia. The analysis of results allowed improved planning of these surgical trips and provided an insight into the late wound healing problems encountered in these patients. The data indicate that complex facial deformity can be treated in a third world setting but with the appreciation that complications are relatively common and that a small percentage of patients $(6 \%)$ would be adversely affected rather than improved by treatment. Further refinements in case selection will hopefully reduce this incidence still further.

This charitable work is only possible because of the dedicated and devoted work of the staff of Project Harar. They have been active in Ethiopia for over 10 years identifying patients and then seeking medical help for these victims of Noma. Their work has been augmented in recent years by Facing
Africa which has had the funds to take small teams of doctors and nurses to Ethiopia. Both of these charities are central to the delivery of health care to this rural population.

1. Maki J, Qualls M, White B, Kleefield S, Crone R. Health impact assessment and short-term medical missions. A methods study to evaluate quality of care. BMC Health Serv Res 2008; 8: 121-128.

2. Williams G. The Addis Ababa fistula hospital: an holistic approach to the management of patients with vesicovaginal fistulae. Surgeon 2007; 5: 54-57.

3. Nicolai J P, Grieb N Van Twisk R, Krause-Bergmann A. Interplast in India. Review of 14 years. Ann Chir Plast Esthet 2004; 49: 291-293.

4. Bos K, Marck K. The surgical treatment of Noma Alphen aan den Rijn: Medidact/Belvédèdere, 2006.

5. Enwonwu C 0, Falkler W A, Philips R S. Noma (cancrum oris). Lancet 2006; 368: 147-156.

6. Tempest M N. Cancrum oris. Br J Surg 1966; 53: 949-969.

7. Huijing M, LeRoux F, Mizen K, Combes J et al. Facial reconstruction in the developing world: a complicated matter. J Oral Maxillofac Surg 2009; in press.

8. Martin D, Pascal J F, Baudet J et al. The submental island flap: a new donor site. Anatomy and clinical applications as a free or pedicled flap. Plast Rec Surg 1993; 92: 867-873. 